\title{
Induction Chemotherapy Followed by Radiotherapy versus Concurrent Chemoradiotherapy in elderly patients with nasopharyngeal carcinoma: finding from a propensity-matched analysis
}

\author{
Qi Zeng ${ }^{1,2+}\left(\mathbb{D}\right.$, Jie Wang ${ }^{3 \dagger}$, Xing Lv ${ }^{1,4}$, Jie Li ${ }^{5}$, Li-Jie Yin ${ }^{3}$, Yan-Qun Xiang ${ }^{1,4^{*}}$ and Xiang Guo ${ }^{1,4^{*}}$
}

\begin{abstract}
Background: To date, no guideline is proposed for elderly nasopharyngeal carcinoma (NPC) due to lack of prospective clinical trials. The present study comparing the survivals and toxicities in elderly NPC patients received either induction chemotherapy followed by radiotherapy (IC + RT) or concurrent chemoradiotherapy (CCRT) was therefore undertaken to provide a more accurate basis for future clinical practice.

Methods: The eligible elderly NPC patients were retrospectively enrolled. Propensity score matching generated a matched cohort (1:2) composed from CCRT and IC + RT groups. The survivals and treatment-induced toxicities were compared between two groups. Multivariable analysis was carried to identify significant prognostic factors.

Results: The 5-year overall survival, cancer-specific survival, locoregional failure-free survival, distant failure-free survival for all patients were $58.3 \%, 62.7 \%, 88.7 \%, 83.0 \%$, respectively. No significant survival differences were found between CCRT and IC + RT groups in the propensity-matched cohort. In comparison with the patients who received IC + RT, patients who underwent CCRT were associated with more severe acute toxicities including leucopenia (30 \% vs. $6.8 \%, P=0.005$ ), anemia ( $20 \%$ vs. $4.1 \%, P=0.027$ ), mucositis ( $63.3 \%$ vs. $34.2 \%, P=0.007$ ), weight loss (23.4 \% vs. $4.1 \%, P=0.009)$. Basicranial bone involvement was an independent prognostic factor that predicted all-cause death $(H R=0.553,95 \% \mathrm{Cl} 0.329-0.929 ; P=0.025)$ and cancer specific death $(H R=0.558$, $95 \% \mathrm{Cl} 0.321-0.969 ; P=0.038$ ) in elderly patients.

Conclusions: In the context of no guideline for elderly NPC, the present study suggested IC + RT should be a preferable modality compared with CCRT, with similar treatment outcomes but less acute toxicities.
\end{abstract}

Keywords: Nasopharyngeal carcinoma, Elderly, Chemo-radiotherapy, Survival

\section{Background}

Nasopharyngeal carcinoma (NPC) is a special head and neck cancer in terms of its epidemiology, etiology, clinical presentation, and prognostic factors [1]. The incidence of NPC is increasing with age in the endemic areas, with a peak and subsequently an earlier decline in age-incidence

\footnotetext{
* Correspondence: Xiangyq@sysucc.org.cn; guoxiang_zlyy@163.com ${ }^{\dagger}$ Equal contributors

'State Key Laboratory of Oncology in South China, Collaborative Innovation Center for Cancer Medicine, Guangzhou 510060, China

Full list of author information is available at the end of the article
}

(in middle-age, ages 45-60 years) than seen in any lowrisk population [2]. Elderly NPC patients (age $\geq 60$ years) constitutes about $13.8 \%(1310 / 9527)$ of all NPC [3, 4]. To date, the treatment for geriatric NPC patients generally follows guidelines tailored for non-elderly patients, but the elderly are usually excluded from prospective clinical trials because of restrictive selection criteria. The development of prospective trials for elderly patients has been hindered by the rarity of patients and accrual difficulties due to the prevalence of comorbidities and decreasing organ function in elderly patients. When a prospective 
design is difficult to achieve, the rigorously designed retrospective study is of paramount importance in the light of evidence that NPC has certain distinctive characteristics when it occurs in elderly patients [4].

A retrospectively matched cohort study [3] of chemoradiotherapy versus radiotherapy alone in elderly NPC patients from our institute was published in January 2015. In this study, patients received combined chemoradiotherapy, which defined as induction chemotherapy followed by radiotherapy $(\mathrm{IC}+\mathrm{RT})$ or concurrent chemoradiotherapy(CCRT), have presented significantly better survival compared with patients received RT alone. Moreover, a 2013 matched analysis also showed CCRT significantly improved the survival in elderly NPC [5]. Thus, we were interested to determine which treatment modality (IC + RT or CCRT) was the optimal treatment strategy for elderly NPC patients. According to previous studies in non-elderly patients $[6,7]$, we hypothesized that no significant difference of survival will be observed between IC $+\mathrm{RT}$ and CCRT groups in elderly patients, but more severe treatment-induced toxicities in CCRT group. If our hypothesis is correct, we propose sequential chemoradiotherapy $(\mathrm{IC}+\mathrm{RT})$ should be recommended for elderly NPC patients in view of poorer tolerance to CCRT in elderly patients as opposed to younger ones.

This present study was therefore undertaken to compare the survivals and treatment-induced toxicities between $\mathrm{IC}+\mathrm{RT}$ and CCRT groups using a propensity-matched analysis in elderly NPC patients (age $\geq 60$ years).

\section{Methods}

From January 1998 and December 2003, the patients selected consecutively in our institute met the following criteria: (i) biopsy-proven, previously untreated WHO II or III NPC ; (ii) elderly patient who is 60 years or older; (iii) no second primary tumors; (iv) patients without systemic metastasis; (v) patients received definitive radiotherapy. The study was approved by the Clinical Research Ethics Committee of Sun Yat-sen University Cancer Center. It was a retrospective analysis of routine data and thus we were granted a waiver of individual informed consent. All patients were evaluated by the following examinations before treatment: complete patient history, physical examination, CT or MRI of the neck and nasopharynx, chest radiography, abdominal ultrasonography, and acquisition of whole body bone scans by single photon emission computed tomography (ECT). All patients were restaged according to the sixth edition AJCC/UICC staging system.

\section{Radiotherapy}

All patients received external beam RT by conventional fractionation; Details of RT technique in our cancer center have been reported previously [3]. To put it simply, 64-72 Gy (in 6.5-7 weeks) were delivered to the primary tumor, 60-66 Gy to clinically involved nodes, and 48-50 Gy to uninvolved cervical and supraclavicular areas. Patients with involvement of the skull base were delivered a booster dose ( 8 to 10 Gy per four to five fractions).

\section{Chemotherapy}

The induction or adjuvant chemotherapy (AC) regimen was mainly a combination of cisplatin and 5-fluorouracil (5-Fu), with cisplatin (30 $\mathrm{mg}$ intravenously) given on Day 1-5 and 5-fluorouracil (750 mg intravenously) on Days $1-5$, repeated every 3 weeks. The concurrent chemotherapy regimen was mainly cisplatin alone, with cisplatin $(30-40 \mathrm{mg} / \mathrm{m} 2$ on Day 1 ) given intravenously weekly or cisplatin $(80-100 \mathrm{mg} / \mathrm{m} 2)$ given intravenously 3-weekly. Dose modification was applied, if needed, at doctor's discretion.

\section{Patient assessment and follow-up}

After treatment, patients were assessed every 3 months by the first 3 years, and every 6 months thereafter until the fifth year. The local recurrences were diagnosed on MRI or CT scanning or by fiber optic endoscopy and biopsy. Regional recurrences were diagnosed by physical examination or MRI/intensive CT scans; irresolute cases were confirmed by fine-needle aspiration. Distant metastases were diagnosed by combined modalities including CT or MR, bone scan, abdominal ultrasonography, and chest $\mathrm{x}$-ray. Chemotherapy-related toxicities were graded according to the Common Terminology Criteria for Adverse Events (CTCAE) v4.0 [8]. Acute and late RTrelated toxicities were graded using the Radiation Morbidity Scoring Criteria of the Radiation Therapy Oncology Group [9]. Late toxicities referred to symptoms that occurred or continued beyond 90 days since the commencement of RT.

\section{Statistical analysis}

The primary end points were overall survival (OS), cancer-specific survival (CSS). The secondary end points were local-regional failure-free survival (LR-FFS), and distant failure-free survival (D-FFS). All intervals were calculated from the date of beginning therapy. OS was defined as the time until death from any causes. CSS referred to the time until death from NPC. LR-FFS was defined as the time until the first recurrence in the cervical and/or nasopharyngeal region after radiotherapy. D-FFS was defined as the time until distant metastasis.

Baseline characteristics of patients in the two groups were accessed using descriptive statistics. The statistical results were presented as the mean \pm standard deviation or percentages. Given the differences in the baseline characteristics between the two groups, propensity-score matching was used to identify the cohort of patients 
with similar baseline characteristics. Matching was performed with the use of a 1:2 matching protocol (nearestneighbor) for CCRT and IC + RT groups. The matching covariates consisted of age, gender, $\mathrm{T}$ classification, $\mathrm{N}$ classification, RT dose to nasopharynx and involved cervical lymph node, RT time, cranial nerve involvement, basicranial bone involvement, and family history. Survival analysis was carried out using the Kaplan-Meier method and compared with the log-rank test. The median followup time was calculated using the reverse KM estimator [10]. Univariate analyses with the unadjusted Cox proportional hazards model were performed to calculate the hazard ratio (HR). Multivariate analyses using the Cox proportional hazards model were performed to identify independent prognostic factors through the backward elimination. A two-sided P-value of less than 0.05 was taken as statistically significant. The statistical analyses were performed using SPSS version 19.0 (SPSS, Inc., an IBM Company; Chicago, IL, USA). In addition, the propensitymatched analysis was performed using the MatchIt package [11] in R Statistical Software (version 3.1.3; R Foundation for Statistical Computing, Vienna, Austria).

\section{Results}

Baseline characteristics, survival and patterns of treatment failure in the entire patient

Between January 1998 and December 2003, a total of 498 eligible elderly patients were included in this present study, with a median age of 65 years (60-84 years). The ratio of male to female was $4.53: 1$, with 408 males and 90 females. The clinical stage distribution was: stage I, 23 (4.6\%); stage II, 127 (25.5\%); stage III, 185 (37.1\%), and stage IVa $163(32.7 \%)$. In total, 171 (34.3\%) patients were treated with combined chemo-radiotherapy (CRT) and 327 (65.7 \%) received radiotherapy (RT) alone. The reverse KM estimate of the median follow-up was 64.7 months (95 \% CI: 62.87-66.52 months). The median OS time was 74.6 months. $46(9.2 \%)$ patients developed locoregional relapse, 78 (15.7 \%) developed distant metastases, and 212 (42.6\%) died. The 1-, 3- and 5 -year survival rates for the entire group were as follows: OS, $99.8 \%, 70.2 \%$ and $58.3 \%$; CSS, $99.8 \%, 72.5 \%$ and $62.7 \%$; LR-FFS, $99.6 \%, 91.5 \%$ and $88.7 \%$; and D-FFS, $99.8 \%, 85.4 \%$ and $83.0 \%$.

\section{Treatment Exposure}

One hundred seventy-one patients received combined chemo-radiotherapy. In which, 111 cases received IC, only 73 cases completed a full course of two cycles of IC; 44 cases received CCRT, only 30 cases completed 3weekly concurrent regimens for three cycles or weekly CCRT for at least five cycles; 15 cases received IC + CCRT/AC, only 13 cases completed at least three cycles. Additionally, just 1 case received one cycle of AC. An analysis of IC delivery found patients received fixed lower total doses of each chemotherapeutic drug irrespective of body surface area, primarily as a result of arbitrary dose modification of chemotherapy owing to fear of excessive side-effects. With respect of CCRT, $22.7 \%$ (10/44) patients received decreased doses of cisplatin. The mean total dose of cisplatin was $249 \mathrm{mg}$ vs. $200 \mathrm{mg}(p=0.046)$ between patients received IC $+\mathrm{RT}$ and patients received CCRT. These results showed patients received higher dose of cisplatin in the IC + RT group.

Baseline characteristics between IC $+\mathrm{RT}$ and CCRT groups The baseline characteristics between IC + RT and CCRT groups showed in Table 1 . Before propensity-score matching, there were no significant differences between the two groups regarding the age, gender, $\mathrm{T}$ classification, nasopharynx dose, lymph node dose, RT days, basicranial bone involvement and family history. Compared with the CCRT group, the IC + RT group had significantly more patients developed cranial nerve involvement (20.7 \% VS. $6.8 \%, P=0.037$ ), showed significantly more advanced clinical stage (54.1 \% VS. $40.9 \%, P=0.048)$, and N classification (20.7 \% VS. $4.5 \%, P=0.018)$. With the use of propensity-score matching (1:2), 44 patients who underwent CCRT were matched with 88 patients who underwent IC $+\mathrm{RT}$. After matching, the balance improvement of the mean differences for all variables were $29.8 \%$, and baseline characteristics between the two groups were well balanced (Table 1).

\section{Survival in the propensity score-matched cohort}

As shown in Fig. 1, The 5-year OS for the IC + RT and CCRT groups were $62.1 \%$ and $52.3 \%(P=0.218$, Fig. 1a), respectively. The 5 -year CSS rate in the IC + RT group was $65.2 \%$ compared with $55.7 \%$ in the CCRT group $(P=0.180$, Fig. $1 b)$. The 5 -year LR-FFS for the IC + RT and CCRT groups were $88.2 \%$ and $85.3 \%(P=0.607$, Fig. 1c), respectively. The 5-year D-FFS rate in the IC + RT group was $75.3 \%$ compared with $81.8 \%$ in the CCRT group $(P=0.239$, Fig. $1 d)$. These results showed no significant differences were found between the two groups in OS, FFS, LR-FFS, or D-FFS.

To further clarify the role of IC and CCRT in NPC, Patients received sufficient cycles of IC ( $n=$ $73)$ and CCRT $(n=30)$ were compared using the propensity score matching. Similarly, baseline characteristics were well matched after propensity score matching (Additional file 1: Table S1). Still, no survival benefits were observed between $\mathrm{IC}+\mathrm{RT}$ and CCRT groups for 5-year OS (65.6 \% VS. $57.0 \%, P=$ $0.332)$, CSS (66.7 \% VS. $59.1 \%, P=0.332)$, LR-FFS (88.4 \% VS. 84.3 \%, $P=0.545)$, and D-FFS $(81.6 \%$ VS. $71.9 \%, P=0.952)$. 
Table 1 Baseline characteristics before and after propensity-score matching between IC + RT and CCRT groups

\begin{tabular}{|c|c|c|c|c|c|c|}
\hline \multirow[t]{2}{*}{ Characteristics } & \multicolumn{2}{|l|}{ Before Matching } & \multirow[t]{2}{*}{ P } & \multicolumn{2}{|l|}{ After Matching } & \multirow[t]{2}{*}{$P$} \\
\hline & $\mathrm{IC}+\mathrm{RT}(\mathrm{N}=111)$ & $\operatorname{CCRT}(N=44)$ & & $\mathrm{IC}+\mathrm{RT}(\mathrm{N}=88)$ & $\operatorname{CCRT}(N=44)$ & \\
\hline Age (y) & & & 0.900 & & & 0.506 \\
\hline Mean & 64.09 & 64.59 & & 64.16 & 64.59 & \\
\hline SD & 3.20 & 4.06 & & 3.20 & 4.06 & \\
\hline Gender (\%) & & & 0.059 & & & 1.000 \\
\hline Male & 95(85.6) & $38(86.4)$ & & 76(86.4) & $38(86.4)$ & \\
\hline Female & $16(14.4)$ & $6(13.6)$ & & 12(13.6) & $6(13.6)$ & \\
\hline T-stage (\%) & & & 0.817 & & & 0.404 \\
\hline $\mathrm{T} 1$ & $4(3.6)$ & $1(2.3)$ & & $4(4.5)$ & $1(2.3)$ & \\
\hline $\mathrm{T} 2$ & $21(18.9)$ & $11(25.0)$ & & 16(18.2) & $11(25.0)$ & \\
\hline T3 & 44(39.6) & 16(36.4) & & $36(40.9)$ & 16(36.4) & \\
\hline $\mathrm{T} 4$ & $42(37.8)$ & 16(36.4) & & $32(36.4)$ & $16(36.4)$ & \\
\hline N-stage (\%) & & & 0.018 & & & 0.068 \\
\hline NO & 19(17.1) & $11(25)$ & & 18(20.5) & $11(25)$ & \\
\hline N1 & 24(21.6) & 17(38.6) & & $20(22.7)$ & 17(38.6) & \\
\hline N2 & $45(40.5)$ & 14(31.8) & & $40(45.5)$ & 14(31.8) & \\
\hline N3 & 23(20.7) & $2(4.5)$ & & 10(11.4) & $2(4.5)$ & \\
\hline Clinical stage (\%) & & & 0.048 & & & 0.175 \\
\hline$\|$ & 4(3.6) & $6(13.6)$ & & $4(4.5)$ & $6(13.6)$ & \\
\hline III & $47(42.3)$ & $20(45.5)$ & & 43(48.9) & $20(45.5)$ & \\
\hline IV & $60(54.1)$ & 18(40.9) & & $41(46.6)$ & 18(40.9) & \\
\hline NP dose (Gy) & & & 0.725 & & & 0.704 \\
\hline Mean & 71.03 & 71.23 & & 71.00 & 71.23 & \\
\hline SD & 3.07 & 3.48 & & 3.11 & 3.48 & \\
\hline LN dose (Gy) & & & 0.054 & & & 0.230 \\
\hline Mean & 61.87 & 59.83 & & 61.21 & 59.83 & \\
\hline SD & 5.79 & 6.26 & & 6.13 & 6.26 & \\
\hline RT days & & & 0.390 & & & 0.428 \\
\hline Mean & 45.16 & 47.25 & & 48.53 & 47.25 & \\
\hline SD & 8.79 & 8.32 & & 8.95 & 8.32 & \\
\hline $\mathrm{CNI}(\%)$ & & & 0.037 & & & 0.245 \\
\hline Present & $23(20.7)$ & $3(6.8)$ & & 12(13.6) & $3(6.8)$ & \\
\hline Absent & 88(79.3) & $41(93.2)$ & & $76(86.4)$ & $41(93.2)$ & \\
\hline BBI (\%) & & & 0.387 & & & 0.458 \\
\hline Present & $47(42.3)$ & $22(50.0)$ & & $38(43.2)$ & $22(50.0)$ & \\
\hline Absent & $64(57.7)$ & $22(50.0)$ & & $50(56.8)$ & $22(50.0)$ & \\
\hline Family history (\%) & & & 0.632 & & & 0.907 \\
\hline Present & $6(5.4)$ & $4(9.1)$ & & $6(6.8)$ & $4(9.1)$ & \\
\hline Absent & 105(94.6) & 40(90.9) & & $82(93.2)$ & 40(90.9) & \\
\hline
\end{tabular}

$I C+R T$ induction chemotherapy followed by radiotherapy, CCRT concurrent chemoradiotherapy, NP nasopharynx, LN lymph node, CNI Cranial nerve involvement, $B B I$ Basicranial Bone involvement, SD standard deviation

Univariate and multivariate analysis in the propensity score-matched cohort

As shown in Table 2, in the univariate analysis, treatment group (IC + RT vs. CCRT) was not associated with survival; basicranial bone involvement was significant factor that predicted OS (HR $=0.553 ; 95 \%$ CI $0.329-0.929 ; P=0.025)$ and CSS (HR $=0.558 ; 95 \%$ CI $0.321-0.969 ; P=0.038)$. After adjustment for age (continuous variable), gender 


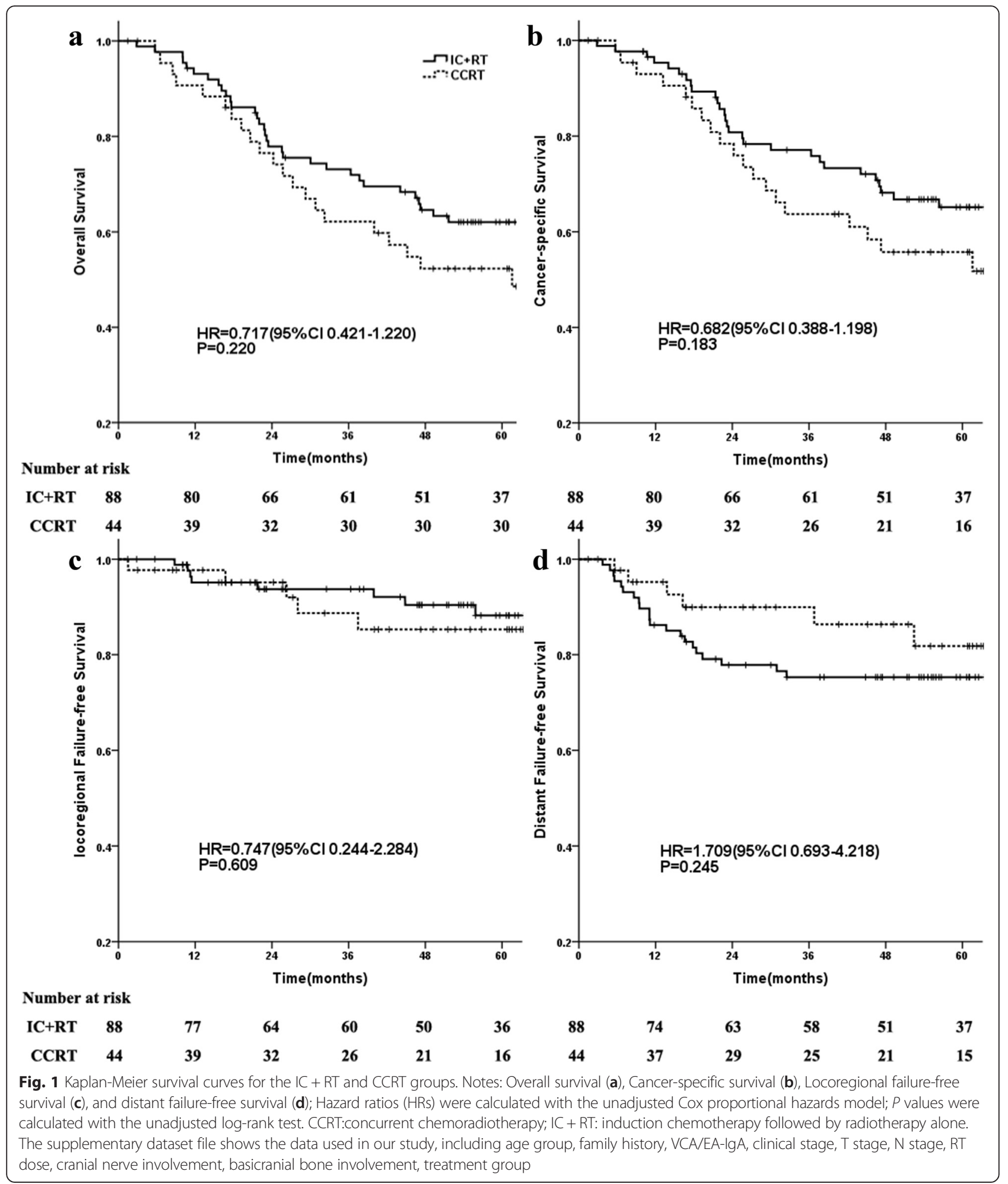

(male vs. female), $\mathrm{T}$ classification (T1-2 vs. T3-4), N classification (N0-1 vs. N2-3), clinical stage (I-II vs. III-IV), nasopharynx dose (continuous variable), lymph node dose (continuous variable), cranial nerve involvement(absent vs. present), basicranial bone involvement(absent vs. present) and family history(absent vs. present), treatment group(IC + RT vs. CCRT) still failed to predict OS $(\mathrm{HR}=0.706 ; 95 \%$ CI $0.412-1.208 ; P=0.204)$, CSS $(\mathrm{HR}=0.708 ; 95 \%$ CI $0.402-1.246 ; P=0.231)$, LRFFS $(H R=0.696 ; 95 \%$ CI $0.207-2.342 ; P=0.558)$, and 
Table 2 Univariate and multivariate analyses in patients received IC $+\operatorname{RT}(n=88)$ or CCRT $(n=44)$ after propensity score matching

\begin{tabular}{|c|c|c|c|c|c|c|c|c|c|}
\hline & & \multirow{2}{*}{$\begin{array}{l}\text { OS } \\
\text { HR }(95 \% \text { Cl) }\end{array}$} & \multicolumn{2}{|l|}{ CSS } & \multicolumn{2}{|l|}{ LRFFS } & \multicolumn{3}{|l|}{ DFFS } \\
\hline & & & $P$ & HR $(95 \% \mathrm{Cl})$ & $P$ & HR $(95 \%$ Cl) & $\bar{P}$ & HR $(95 \%$ Cl) & $P$ \\
\hline \multicolumn{10}{|l|}{ Univeriate parameter } \\
\hline Age & Continuous variable & $1.051(0.977-1.131)$ & 0.185 & $1.046(0.967-1.132)$ & 0.261 & $0.892(0.737-1.079)$ & 0.239 & $1.044(0.945-1.154)$ & 0.399 \\
\hline Gender & male vs. female & $1.301(0.590-2.869)$ & 0.514 & $1.119(0.504-2.487)$ & 0.782 & $2.131(0.277-16.397)$ & 0.467 & $1.434(0.433-4.751)$ & 0.555 \\
\hline T-stage & T1-2 vs. T3-4 & $0.907(0.496-1.659)$ & 0.752 & $0.974(0.518-1.833)$ & 0.936 & $2.725(0.915-8.115)$ & 0.072 & $0.984(0.418-2.320)$ & 0.971 \\
\hline $\mathrm{N}$-stage & No-1vs. N2-3 & $0.902(0.538-1.512)$ & 0.902 & $1.087(0.628-1.883)$ & 0.765 & $1.200(0.403-3.570)$ & 0.744 & $0.763(0.361-1.614)$ & 0.479 \\
\hline Clinical stage & |-|| vs. |||-IV & $0.805(0.291-2.228)$ & 0.805 & $0.929(0.334-2.580)$ & 0.887 & $2.088(0.462-9.430)$ & 0.338 & $0.436(0.059-3.209)$ & 0.415 \\
\hline NP dose (Gy) & Continuous variable & $1.007(0.930-1.090)$ & 0.862 & $1.002(0.921-1.090)$ & 0.960 & $0.925(0.808-1.058)$ & 0.253 & $1.042(0.923-1.175)$ & 0.510 \\
\hline LN dose (Gy) & Continuous variable & $1.023(0.980-1.068)$ & 0.292 & $1.021(0.975-1.068)$ & 0.380 & $0.946(0.871-1.027)$ & 0.187 & $1.057(0.993-1.125)$ & 0.083 \\
\hline RT Days & Continuous variable & $1.006(0.981-1.032)$ & 0.623 & $1.010(0.984-1.037)$ & 0.451 & $0.954(0.887-1.026)$ & 0.203 & $1.013(0.977-1.050)$ & 0.493 \\
\hline Treatment group & IC + RT vs. CCRT & $0.717(0.421-1.220)$ & 0.220 & $0.682(0.388-1.198)$ & 0.183 & $0.747(0.244-2.284)$ & 0.609 & $1.709(0.693-4.218)$ & 0.245 \\
\hline Cranial nerve involvement & absent vs. present & $0.781(0.354-1.726)$ & 0.542 & $0.663(0.298-1.476)$ & 0.314 & $0.581(0.128-2.628)$ & 0.481 & $0.657(0.228-1.896)$ & 0.437 \\
\hline Basicranial Bone involvement & absent vs. present & $0.553(0.329-0.929)$ & 0.025 & $0.558(0.321-0.969)$ & 0.038 & $0.784(0.263-2.341)$ & 0.663 & $0.712(0.339-1.497)$ & 0.371 \\
\hline Family history & absent vs. present & $1.142(0.413-3.155)$ & 0.798 & $1.349(0.420-4.335)$ & 0.615 & $22.74(0.003-25.96)$ & 0.494 & $0.655(0.197-2.171)$ & 0.489 \\
\hline \multicolumn{10}{|l|}{ Multivariate parameter $^{\mathrm{a}}$} \\
\hline Treatment group & IC + RT vs. CCRT & $0.706(0.412-1.208)$ & 0.204 & $0.708(0.402-1.246)$ & 0.231 & $0.696(0.207-2.342)$ & 0.558 & $1.627(0.658-4.023)$ & 0.292 \\
\hline Basicranial Bone involvement & absent vs. present & $0.553(0.329-0.929)$ & 0.025 & $0.558(0.321-0.969)$ & 0.038 & $0.246(0.044-1.382)$ & 0.111 & $0.760(0.337-1.715)$ & 0.508 \\
\hline T-stage & T1-2 vs. T3-4 & $1.347(0.638-2.842)$ & 0.435 & $1.490(0.675-3.289)$ & 0.324 & $6.833(1.224-38.148)$ & 0.028 & $1.355(0.481-3.819)$ & 0.565 \\
\hline
\end{tabular}

CI confidence interval, IC+RT induction chemotherapy followed by radiotherapy, CCRT concurrent chemoradiotherapy, NP nasopharynx, LN lymph node

a Other covariates not shown $(P>0.05)$ 
D-FFS $(H R=1.627 ; 95 \%$ CI $0.658-4.023 ; P=0.292)$. The significant variable that predicted all-cause death and cancer specific death was basicranial bone involvement. Additionally, $\mathrm{T}$ classification was independent prognostic factor that predicted localregional tumor recurrence.

\section{Treatment toxicities}

To compare the incidence of treatment toxicities between IC $+\mathrm{RT}$ and CCRT groups, patients received sufficient courses of IC + RT or CCRT were chose. As listed in Table 3. Regarding hematologic toxicities, incidences of grade III and IV leukopenia (30\% vs. $6.8 \%, P=0.005)$, anemia (20 \% vs. $4.1 \%, P=0.027)$ and granulocytopenia $(26.7 \%$ vs. $5.5 \%, P=0.007)$ were significantly higher in the CCRT group. No significant difference in thrombocytopenia $(13.3 \%$ vs. $2.7 \%, P=0.105)$ was found between the two groups. With respect to nonhematologic toxicity, the incidences of grade III and IV mucositis $(63.3 \%$ vs. $34.2 \%, P=$ $0.007)$, skin reaction $(20.0 \%$ vs. $4.1 \%, P=0.027)$, and weight loss $(23.4 \%$ vs. $4.1 \%, P=0.027)$ were significantly higher in the CCRT group; while no significant differences were detected regarding the incidence of severe vomiting and hepatic impairment between the groups. In addition, no severe renal toxicity was seen in either group. Late toxicities were also analyzed in our study. Unlike acute

Table 3 Incidences of serious toxicities during radiotherapy course between IC+RT and CCRT groups

\begin{tabular}{|c|c|c|c|c|c|}
\hline \multirow[t]{2}{*}{ Toxicity } & \multicolumn{2}{|c|}{ IC + RT $(\%, N=73)$} & \multicolumn{2}{|c|}{ CCRT $(\%, N=30)$} & \multirow[t]{2}{*}{$P$} \\
\hline & Grade 3 & Grade 4 & Grade 3 & Grade 4 & \\
\hline \multicolumn{6}{|l|}{ Acute toxicity } \\
\hline Leukopenia & $5(6.8)$ & 0 & $7(23.3)$ & $2(6.7)$ & 0.005 \\
\hline Granulocytopenia & $4(5.5)$ & 0 & $6(20.0)$ & $2(6.7)$ & 0.007 \\
\hline Thrombocytopenia & $2(2.7)$ & 0 & $3(10.0)$ & $1(3.3)$ & 0.105 \\
\hline Anemia & $2(2.7)$ & $1(1.4)$ & $4(13.3)$ & $2(6.7)$ & 0.027 \\
\hline Vomiting & 0 & 0 & $2(6.7)$ & 0 & 0.149 \\
\hline Mucositis & 25(34.2) & 0 & 16(53.3) & $3(10.0)$ & 0.007 \\
\hline Skin reaction & $3(4.1)$ & 0 & $5(16.7)$ & $1(3.3)$ & 0.027 \\
\hline Hepatic impairment & $1(1.4)$ & 0 & $1(3.3)$ & 0 & 1.000 \\
\hline Renal impairment & 0 & 0 & 0 & 0 & \\
\hline Weight loss & $3(4.1)$ & 0 & $5(16.7)$ & $2(6.7)$ & $2(6.7)$ \\
\hline \multicolumn{6}{|l|}{ Late toxicity } \\
\hline Xerostomia & $3(4.1)$ & 0 & $2(6.7)$ & 0 & 0.965 \\
\hline Subcutaneous Fibrosis & $5(6.8)$ & 0 & $2(6.7)$ & 0 & 1.000 \\
\hline Temporal lobe necrosis & $2(2.7)$ & 0 & $1(3.3)$ & 0 & 1.000 \\
\hline Trismus & $2(2.7)$ & 0 & 0 & 0 & 0.897 \\
\hline Dysphagia & $3(4.1)$ & 0 & $2(6.7)$ & 0 & 0.965 \\
\hline Cranial neuropathy & $1(1.4)$ & 0 & 0 & 0 & 1.000 \\
\hline
\end{tabular}

toxicities, the incidence of severe late toxicities was comparable between both groups (Table 3 ).

\section{Discussion}

Numerous studies were carried out to address the use of chemotherapy in combination with RT for the care of locoregionally advanced NPC (which involved only a few elderly patients). A 2012 meta-analysis [12] which included six trials in IC + RT group $(n=1418)$ and five in AC group $(n=1187)$ found that IC + RT can effectively enhance OS and reduce the risk of distant failure. However, a recent another meta-analysis [13] that included 19 trials and 4806 patients confirmed the addition of chemotherapy to radiotherapy significantly improved OS in favor of CCRT + AC and CCRT without AC but not $\mathrm{AC}$ alone or IC+RT alone. To date, it is generally believed that CCRT is the most efficacious modality for non-elderly patients. In contrast, previous studies for elderly NPC patients have shown either IC + RT or CCRT can improve the survival of elderly NPC patients $[3,5]$. But which is a favorable regimen remains unclear, it is necessary to elucidate the roles of IC + RT or CCRT in elderly NPC patients given the poor compliance with combined chemoradiotherapy, especially CCRT.

In the present propensity-matched study, the results confirmed our hypothesis. No significant differences between $\mathrm{IC}+\mathrm{RT}$ and CCRT groups were found regarding overall survival, cancer-specific survival, locoregional failure-free survival, or distant failure-free survival. Patients received sufficient cycles of IC $(n=73)$ and CCRT ( $n=30)$ were further compared using the propensitymatched analysis. We found that 5-year OS, CSS, and DFFS were higher in the IC + RT group compared with CCRT group, but the difference was not statistical significance(OS:65.6 \% VS. $57.0 \%, P=0.332$; CSS: $65.6 \%$ VS. $57.0 \%, P=0.332$; D-FFS: $81.6 \%$ VS. $71.9 \%, P=0.952$ ). This was mainly due to the relatively small matched pairs even using 1:2 matching on the propensity score (Additional file 1: Table S1).

The most probable explanation for this negative result might either IC + RT or CCRT can improve the locoreginal control, but failed to further decrease the distant metastasis compared with radiotherapy alone. NPC is a highly chemosensitive solid tumor [14]. Induction chemotherapy can increase tumor sensitivity to radiation through shrinking the primary tumor and improving the intratumoral blood supply and re-oxygenation, which also lead to an increased safety margin between the radiation volume and the tumor volume $[15,16]$; For patients received CCRT, the synergistic effects between cytotoxic agents and radiation can also improve the locoreginal control of the primary tumor [17]. Thus, the radiosensitizing effect of chemotherapy is similar in patients received IC $+\mathrm{RT}$ or CCRT. However, neither $\mathrm{IC}+\mathrm{RT}$ nor CCRT can further improve the D-FFS in 
elderly patients, which is mainly because the elderly patients have worse compliance with combined chemoradiotherapy compared to the non-elderly patients $[3,5]$. In addition, the effective of chemotherapy is involved with dose intensity, but our data showed that elderly NPC patients often received fixed lower total doses of each drug irrespective of body surface area, mainly as a result of arbitrary dose modification of chemotherapy owing to fear of excessive side-effects, which was also seen in the other studies [18, 19]. In clinical practice, because there were no proposed guidelines for elderly NPC patients, oncologists often attached importance to the treatment-related toxicities and preferred a lower dose without evaluation. As a consequence, this conservative treatment selection potentially prevented some elderly patients from longer survival [5]. More importantly, distant metastases remain the predominant pattern of treatment failure in NPC patients [20], previous studies have shown even IC + CCRT failed to decrease the distant metastases [6, 7]. Geriatric oncologists should exploit other advances made in the management of non-elderly NPC, such as the addition of targeted agents to chemoradiotherapy [21, 22], which have obtained some promising outcomes (2-year D-FFS of about $90 \%$ ).

It is generally accepted that the elderly cancer patients experienced an increased treatment-induced toxicity $[19,23]$. Some reasons accounting for this included more common comorbidities [24], an increased exposure to a drug (e.g. by impaired renal function or by prolonged half-life due to decreased elimination) and changes in pharmacodynamics caused by increased vulnerability of organs with age [25]. However, previous studies shown the rates of severe acute and late toxicities caused by CCRT in elderly patients were similar with younger patients $[5,26]$. It is likely that a selection and referral bias in these studies lead to accrual of only fit elderly patients [25]. In the present study, the toxicities in elderly patients received sufficient courses of IC + RT or CCRT were compared. Although the incidence of severe late toxicities was comparable between both groups, patients received CCRT were associated with more acute toxicities, as compared with patients received IC + RT, including leucopenia, granulocytopenia, anemia, mucositis, skin reaction, weight loss (Table 3). The high incidence of severe acute toxicities in CCRT group may interrupt oncologic treatment, increase the risk of unplanned hospitalization, and seriously affect the quality of life in elderly patients $[27,28]$. Thus, geriatric oncologists should pay more attention to elderly NPC patients received CCRT in future.

In spite of no significant survival differences between CCRT and IC + RT groups, the entire patient cohort was analyzed to identify valuable prognostic factors in the elderly NPC patients. Multivariate analysis showed basicranial bone involvement remained an independent prognostic factor that predicted all-cause death and cancer specific death in elderly patients and T classification predicted localregional tumor recurrence. Contrary to several non-elderly series [29-31], age, gender, $\mathrm{N}$ classification, and family history failed to predict all survival endpoints for elderly patients. The results suggested the potentially different clinical characteristics between the elderly patients and their younger ones.

To the best of our knowledge, there is very little published information regarding the optimal chemotherapy modalities of elderly NPC. In the past, the elderly NPC patients were treated very differently at different cancer centers. Our intention was not to test a novel therapy but to ensure an equivalent therapeutic effect and less treatment-induced toxicities for the elderly patients. Some limitations in our study should be considered. Firstly, this was a nonrandomized, retrospective study and hence suffered from potential selection bias despite robust propensity-score matching. Secondly, comorbidities were not further assessed, which may have effect on survival, although cancer-specific survival was used to exclude death due to comorbidities. Finally, all patients were treated using conventional RT technique, whether it is preferable to combine chemotherapy and intensity-Modulated Radiation Therapy (IMRT) should be investigated in future.

\section{Conclusions}

In summary, the present propensity-matched study demonstrated the elderly NPC patients received IC + RT achieve similar survival outcomes compared with patients received CCRT, but with less treatment-induced acute toxicities. In the context of no guideline for elderly NPC, the present study suggested IC + RT should be a preferable modality compared with CCRT. It is hoped that the current outcomes could provide a more accurate basis for designing future clinical trials.

\section{Additional files}

Additional file 1: Table S1. Baseline characteristics before and after propensity-score matching in patients received sufficient cycles of IC + RT and CCRT. (DOC $95 \mathrm{~kb}$ )

Additional file 2: List of elderly patients with nasopharyngeal carcinoma in our study. (XLSX $49 \mathrm{~kb}$ )

\section{Abbreviations}

CCRT, concurrent chemoradiotherapy; CRT, combined chemo-radiotherapy; CSS, cancer-specific survival; CTCAE, the Common Terminology Criteria for Adverse Events; D-FFS, distant failure-free survival; ECT, single photon emission computed tomography; HR, hazard ratio; IC + RT, induction chemotherapy followed by radiotherapy; LRFFS, local-regional failure-free survival; NPC, Nasopharyngeal carcinoma; OS, overall survival; RT, radiotherapy

\section{Acknowledgements}

Authors are indebted to two reviewers for their valuable comments and suggestions. These authors also acknowledge the department of medical records for permission to access the linked databases. Finally, Dr. Zeng would like to thank particularly the invaluable support received from his wife, Mrs. Shuang Li, over the years. 


\section{Funding}

This work was supported by International Program for Ph.D. Candidates,Sun YatSen University; National Natural Science Foundation of China (No: 81572665; 81472525); High Technology Research and Development Program of China (863 Program) (No. 2012AA02A501); and Science and Technology Planning Project of Guangdong Province, China (No: 2014A050503033; No. 2014B020212017). The funders had no role in study design, data collection and analysis, decision to publish, or preparation of the manuscript.

\section{Availability of data and materials}

All data generated or analysed during this study were included in Additional file 2.

\section{Authors' contributions}

QZ, JW, YQX, and XG were involved in the conception and design of the study; data acquisition, analysis, interpretation of results, drafting the manuscript. QZ and XL were involved in the acquisition of source datasets, participated in the analysis and interpretation of data. JL and LJY participated in data analysis and revised the manuscript critically. All authors read and approved the final manuscript.

\section{Competing interests}

The authors declare that they have no competing interests.

\section{Consent for publication}

Not applicable.

\section{Ethics approval and consent to participate}

The study was approved by the Clinical Research Ethics Committee of Sun Yat-sen University Cancer Center. It was a retrospective analysis of routine data and thus we were granted a waiver of individual informed consent.

\section{Author details}

'State Key Laboratory of Oncology in South China, Collaborative Innovation Center for Cancer Medicine, Guangzhou 510060, China. ${ }^{2}$ Department of Interventional Oncology, Sun Yat-sen University Cancer Center, Guangzhou 510060, China. ${ }^{3}$ Department of Radiation Oncology, Dalian Municipal Central Hospital, Dalian 116033, China. ${ }^{4}$ Department of Nasopharyngeal Carcinoma, Sun Yat-sen University Cancer Center, 651 Dongfeng Road East, Guangzhou 510060, People's Republic of China. ${ }^{5}$ Department of Breast and Thyroid Surgery, The First Affiliated Hospital of Sun Yat-Sen University, Guangzhou, Guangdong 510080, People's Republic of China.

\section{Received: 23 March 2016 Accepted: 2 August 2016}

\section{Published online: 30 August 2016}

\section{References}

1. Casanova M, Bisogno G, Gandola L, Cecchetto G, Di Cataldo A, Basso E, Indolfi P, D'Angelo P, Favini F, Collini P, et al. A prospective protocol for nasopharyngeal carcinoma in children and adolescents: the Italian Rare Tumors in Pediatric Age (TREP) project. Cancer. 2012;118(10):2718-25.

2. Bray F, Haugen M, Moger TA, Tretli S, Aalen OO, Grotmol T. Age-incidence curves of nasopharyngeal carcinoma worldwide: bimodality in low-risk populations and aetiologic implications. Cancer Epidemiol Biomarkers Prev. 2008;17(9):2356-65.

3. Zeng Q, Xiang YQ, Wu PH, Lv X, Qian CN, Guo X. A matched cohort study of standard chemo-radiotherapy versus radiotherapy alone in elderly nasopharyngeal carcinoma patients. PLoS One. 2015:10(3):e119593.

4. Zeng Q, Guo X, Li NW, Xiang YQ, Cao SM, Hong MH. [Clinical characteristics and prognosis of aged nasopharyngeal carcinoma patients: a report of 313 cases]. Ai Zheng. 2008;27(3):289-94.

5. Liu H, Chen QY, Guo L, Tang LQ, Mo HY, Zhong ZL, Huang PY, Luo DH, Sun $R$, Guo X, et al. Feasibility and efficacy of chemoradiotherapy for elderly patients with locoregionally advanced nasopharyngeal carcinoma: results from a matched cohort analysis. Radiat Oncol. 2013;8(1):70.

6. Huang PY, Cao K, Guo X, Mo HY, Guo L, Xiang YQ, Deng MQ, Qiu F, Cao SM, Guo Y, et al. A randomized trial of induction chemotherapy plus concurrent chemoradiotherapy versus induction chemotherapy plus radiotherapy for locoregionally advanced nasopharyngeal carcinoma. Oral Oncol. 2012;48(10):1038-44.
7. Fountzilas G, Ciuleanu E, Bobos M, Kalogera-Fountzila A, Eleftheraki AG, Karayannopoulou G, Zaramboukas T, Nikolaou A, Markou K, Resiga L, et al. Induction chemotherapy followed by concomitant radiotherapy and weekly cisplatin versus the same concomitant chemoradiotherapy in patients with nasopharyngeal carcinoma: a randomized phase II study conducted by the Hellenic Cooperative Oncology Group (HeCOG) with biomarker evaluation. Ann Oncol. 2012;23(2):427-35.

8. CTCAE V4.0. http://www.eortc.be/services/doc/ctc/CTCAE_4.03_2010-06-14_ QuickReference_5x7.pdf. In

9. Cox JD, Stetz J, Pajak TF. Toxicity criteria of the Radiation Therapy Oncology Group (RTOG) and the European Organization for Research and Treatment of Cancer (EORTC). Int J Radiat Oncol Biol Phys. 1995;31(5):1341-6.

10. Schemper M, Smith TL. A note on quantifying follow-up in studies of failure time. Control Clin Trials. 1996;17(4):343-6.

11. Justus J, Randolph, Kristina F, Austin Kureethara Manuel, Joseph L. BJ. A Step-by-Step Guide to Propensity Score Matching in R. Pract Assessment, Res Eval. 2014:8(19).

12. OuYang PY, Xie C, Mao YP, Zhang Y, Liang XX, Su Z, Liu Q, Xie FY. Significant efficacies of neoadjuvant and adjuvant chemotherapy for nasopharyngeal carcinoma by meta-analysis of published literature-based randomized, controlled trials. Ann Oncol. 2013;24(8):2136-46.

13. Blanchard P, Lee A, Marguet S, Leclercq J, Ng WT, Ma J, Chan AT, Huang PY, Benhamou E, Zhu G et al. Chemotherapy and radiotherapy in nasopharyngeal carcinoma: an update of the MAC-NPC meta-analysis. Lancet Oncol. 2015;16(6): 645-55.

14. Songthong A, Chakkabat C, Kannarunimit D, Lertbutsayanukul C. Efficacy of intensity-modulated radiotherapy with concurrent carboplatin in nasopharyngeal carcinoma. Radiol Oncol. 2015;49(2):155-62.

15. Ma J, Mai HQ, Hong MH, Min HQ, Mao ZD, Cui NJ, Lu TX, Mo HY. Results of a prospective randomized trial comparing neoadjuvant chemotherapy plus radiotherapy with radiotherapy alone in patients with locoregionally advanced nasopharyngeal carcinoma. J Clin Oncol. 2001;19(5):1350-7.

16. Teo PM, Chan AT, Lee WY, Leung TW, Johnson PJ. Enhancement of local control in locally advanced node-positive nasopharyngeal carcinoma by adjunctive chemotherapy. Int J Radiat Oncol Biol Phys. 1999;43(2):261-71.

17. Seiwert TY, Salama JK, Vokes EE. The concurrent chemoradiation paradigmgeneral principles. Nat Clin Pract Oncol. 2007;4(2):86-100.

18. Ho HC, Su YC, Lee MS, Hsiao SH, Hwang JH, Lee CC, Hung SK. A preliminary result of concurrent chemoradiation with weekly cisplatin in elderly nasopharyngeal carcinoma patients. Acta Otolaryngol. 2008;128(8):930-5.

19. Lichtman SM, Buchholtz M, Marino J, Schulman P, Allen SL, Weiselberg L, Budman D, DeMarco L, Schuster M, Lovecchio J, et al. Use of cisplatin for elderly patients. Age Ageing. 1992;21(3):202-4.

20. Lee AW, Lin JC, Ng WT. Current management of nasopharyngeal cancer. Semin Radiat Oncol, 2012:22(3):233-44.

21. Lee NY, Zhang Q, Pfister DG, Kim J, Garden AS, Mechalakos J, Hu K, Le QT, Colevas AD, Glisson BS, et al. Addition of bevacizumab to standard chemoradiation for locoregionally advanced nasopharyngeal carcinoma (RTOG 0615): a phase 2 multi-institutional trial. Lancet Oncol. 2012:13(2):172-80.

22. Ma BB, Kam MK, Leung SF, Hui EP, King AD, Chan SL, Mo F, Loong H, Yu BK, Ahuja $\mathrm{A}$, et al. A phase II study of concurrent cetuximab-cisplatin and intensitymodulated radiotherapy in locoregionally advanced nasopharyngeal carcinoma. Ann Oncol. 2012:23(5):1287-92.

23. Minami H, Ohe Y, Niho S, Goto K, Ohmatsu H, Kubota K, Kakinuma R, Nishiwaki Y, Nokihara H, Sekine I, et al. Comparison of pharmacokinetics and pharmacodynamics of docetaxel and Cisplatin in elderly and nonelderly patients: why is toxicity increased in elderly patients? I Clin Oncol. 2004;22(14):2901-8.

24. Guo R, Chen XZ, Chen L, Jiang F, Tang LL, Mao YP, Zhou GQ, Li WF, Liu LZ, Tian $L$, et al. Comorbidity predicts poor prognosis in nasopharyngeal carcinoma: development and validation of a predictive score model. Radiother Oncol. 2015;114(2):249-56.

25. Wedding U, Honecker F, Bokemeyer C, Pientka L, Hoffken K. Tolerance to chemotherapy in elderly patients with cancer. Cancer Control. 2007;14(1):44-56.

26. Michal SA, Adelstein DJ, Rybicki LA, Rodriguez CP, Saxton JP, Wood BG, Scharpf J, Ives DI. Multi-agent concurrent chemoradiotherapy for locally advanced head and neck squamous cell cancer in the elderly. Head Neck. 2012:34(8):1147-52.

27. Manzano JG, Luo R, Elting LS, George M, Suarez-Almazor ME. Patterns and predictors of unplanned hospitalization in a population-based cohort of elderly patients with GI cancer. J Clin Oncol. 2014;32(31):3527-33. 
28. Repetto L, Ausili-Cefaro G, Gallo C, Rossi A, Manzione L. Quality of life in elderly cancer patients. Ann Oncol. 2001;12 Suppl 3:S49-52.

29. Huang PY, Wang CT, Cao KJ, Guo X, Guo L, Mo HY, Wen BX, Wu YS, Mai HQ, Hong MH. Pretreatment body mass index as an independent prognostic factor in patients with locoregionally advanced nasopharyngeal carcinoma treated with chemoradiotherapy: findings from a randomised trial. Eur J Cancer. 2013;49(8):1923-31.

30. Ouyang PY, Su Z, Mao YP, Liang XX, Liu Q, Deng W, Xie FY. Prognostic impact of cigarette smoking on the survival of patients with established nasopharyngeal carcinoma. Cancer Epidemiol Biomarkers Prev. 2013;22(12):2285-94.

31. Chen L, Hu CS, Chen XZ, Hu GQ, Cheng ZB, Sun Y, Li WX, Chen YY, Xie FY, Liang SB, et al. Concurrent chemoradiotherapy plus adjuvant chemotherapy versus concurrent chemoradiotherapy alone in patients with locoregionally advanced nasopharyngeal carcinoma: a phase 3 multicentre randomised controlled trial. Lancet Oncol. 2012;13(2):163-71.

Submit your next manuscript to BioMed Central and we will help you at every step:

- We accept pre-submission inquiries

- Our selector tool helps you to find the most relevant journal

- We provide round the clock customer support

- Convenient online submission

- Thorough peer review

- Inclusion in PubMed and all major indexing services

- Maximum visibility for your research

Submit your manuscript at www.biomedcentral.com/submit
) Biomed Central 